\title{
Relationship between Emotional Intelligence and Leadership Styles: A Case Study of Leaders in Selected Banking Institutions in Kenya
}

\author{
Sr. Margaret Chepng'eno ${ }^{1}$, Dr. Thomas Ngui ${ }^{2}$ \\ ${ }^{1}$ Catholic University of Eastern Africa, School of Business, Nairobi, Kenya \\ ${ }^{2}$ Catholic University of Eastern Africa, School of Business, Nairobi, Kenya
}

\begin{abstract}
This study sought to determine the relationship between Emotional Intelligence (EI) and leadership styles of managers among selected banking institutions in Kenya. It proposed that EI, which is the ability to perceive, understand and manage emotions predicts transformational leadership (TL) style. The leaders' EI scores were obtained by administering the Emotional and Social Competency Inventory (ESCI), and to measure perceived leadership styles, the raters completed the Multifactor Leadership Questionnaire (MLQ-5x). A sample of 60 leaders and 240 raters was drawn from six banks. Spearman's Correlation was carried out on the data and the results indicated a positive relationship between EI scores of leaders and TL style. Further analysis indicated a positive relationship between EI and contingent reward and active MBE components of transactional leadership. On the contrary negative relationships were revealed between EI and passive MBE as well as laissez-faire leadership style, thus it was concluded that EI predicts leadership styles.
\end{abstract}

Keywords: Emotional Intelligence, Transformational, Transactional, Laissez-faire

\section{INTRODUCTION}

The critical role of leadership in organizational success justifies the emerging extensive research in the area of leadership, and the quest for the most appropriate of its styles, as well as the factors that predict it. In the literature, effective leaders have been linked to those demonstrating transformational leadership (TL) behaviours because transformational leaders have been known to create and articulate an attractive vision, and to inspire and revitalize their followers to perform beyond their expectation to achieve that vision [41]. This is beneficial to every organization but more so to banking institutions that contend with financial crisis of every kind. While most studies describe effective leaders, what they do and how they make decisions, the effects of their feelings and moods, and generally, the role of emotions in the leadership process, are often not explicitly considered [24]. Moreover their selection disregards emotional aspects. This is partly because for many centuries decision making has been attributed primarily to cognitive ability, and feelings and emotions have been regarded as impediment to rational choice [30]. Nonetheless, psychologists have begun to assert that decision making relies upon emotional assessment. In fact, individuals who cannot reference emotional memory would be unable to make rational decisions at all [35]. Studies on leadership have also indicated unexplained variance in performance that is not accounted for by general intelligence [17] and this has led to extensive research on EI.

Emotional Intelligence refers to the ability to identify emotions, to manage and to use them to guide decision making [47]. In leadership, this enables leaders to understand others' needs and to develop strategies for fulfilling them in order to influence their behaviour. This is significant since leadership relates to the process of influencing others to understand and agree on what needs to be done and how to do it, and facilitating efforts to accomplish objectives [50]. Generally the role of EI in leadership among banking institutions in Kenya could be described as blurred, a situation partly caused by disregard of emotional factors in decision making where the focus is on task and meeting targets.

\section{Problem Statement}

The banking sector has evolved drastically; commercial banks have become very competitive resulting in various strategies for attracting new customers and retaining old ones. To become more customer-focused banks have introduced various interventions that improve their financial base but not without negative impact on employees' mental and psychological wellbeing. Overloading and extreme burden of work, stringent work deadlines, extended working hours, fear of termination of job 
Sr. Margaret Chepng'eno \& Dr. Thomas Ngui "Relationship between Emotional Intelligence and Leadership Styles: A Case Study of Leaders in Selected Banking Institutions in Kenya"

contracts, etc. are common problems among bank employees which have resulted in extremely high level of stress and emotional imbalance. Fear of uncertainty during periods of financial crisis also often leads to employees' negative and defensive attitude, their turnover and eventual customer loss [19].

The prevailing work situations in the banks reinforce the need for leaders who are in touch with employees' feelings and emotions and who can effectively manage these emotions so as to minimize their negative impact. There is also need for leaders who not only focus on the task, but also maintain a relationship with them so that while upholding a position of authority, they are still considered friendly, understanding and considerate. The effort of building intimate relationships, based on emotions, is particularly evident in transformational leaders who enable their followers to excel beyond expectations by unifying their beliefs and values [21]. Researchers [6] [44] have confirmed that TL is positively related to employee job satisfaction, commitment and performance in the banking sector. This then raises the question: do emotionally intelligent leaders provide such kind of leadership? Emotionally intelligent leaders are known for their social charm, empathy, self-awareness and self-control [23]; how do these attributes relate to TL?

Although many studies have been done separately in the areas of leadership and EI, the relationship between these variables is not widely tested, probably because people's attitude towards EI has, to some extent, been influenced by critics who disregard its significance. For example, Antonakis [1] asserts that if anything matters for leader-member relations, it is personality and IQ and definitely not EI. Such arguments seem to have influenced leader selection approaches that organizations adopt to the extent that identification of employees for leadership positions tend to be based primarily on intellectual abilities and experience whereas emotional attributes are downplayed.

Many studies have demonstrated the effectiveness of TL behavour in organizations [32] but there is a relative lack of research regarding the antecedents of these behaviours [45]. Previous studies link it to biographical background factors [4], intelligence [2], psychological factors [13], gender [34], and leader fit [26], but in the overall the capacity of these individual differences to predict TL has been inconclusive and as a consequence the suggestion that other unexplored factors such as EI may play a prominent role in predicting TL behaviours [38] still holds. The purpose of this study, therefore, was to test the relationship between EI and leadership styles as it attempted to fill the elusive dimension of emotions in leadership. The study adds to the body of knowledge in the area of leadership by introducing EI as one of the factors that organizations could use to identify effective leaders.

\section{RESEARCH OBJECTIVES}

The main aim of this study was to establish the relationship between EI and leadership styles

\section{Research Hypotheses}

$$
\begin{aligned}
& \mathrm{H}_{1} \text { : There is a positive relationship between EI and Transformational leadership } \\
& \mathrm{H}_{2} \text { : There is a positive relationship between EI and transactional leadership } \\
& \mathrm{H}_{3} \text { : There is a negative relationship between EI and Laissez-faire Leadership }
\end{aligned}
$$

\section{THEORETICAL AND EMPIRICAL REVIEW}

This study focused on Goleman's Mixed Model of emotional intelligence [25] and the Full-Range Theory (FRT) of Leadership proposed by Bass and Avolio [11]. In his model that combines mental abilities and personality traits, Goleman [25] identified five EI components categorized as personal competences and social competences. The five components were eventually revised and Boyatzis and Goleman [15] provide the current version with four components (Self-awareness, Self-Management, Social Awareness and Relationship Management) and twelve competencies. Self-awareness is captured in emotional self-awareness competency, and refers to the ability to understand own emotions and their effects on performance. Self management; the ability to effectively manage own emotions, is captured in emotional self-control, achievement orientation, positive outlook and adaptability. Social Awareness on the other relates to recognizing and understanding emotions of others as portrayed in empathy and organizational awareness. Finally relationship management, which is captured in five competencies: influence, coach and mentor, conflict management, inspirational leadership and teamwork is the application of emotional understanding in dealing with others. 
Sr. Margaret Chepng'eno \& Dr. Thomas Ngui "Relationship between Emotional Intelligence and Leadership Styles: A Case Study of Leaders in Selected Banking Institutions in Kenya"

Babooa [7] defines leadership as the process of influencing behaviour in such a way that willing commitment towards organizational goals is achieved and thus the importance of good leadership and the extensive research in the area which have led to numerous theories that explain it. The full-rage theory (FRT) of leadership consists of nine factors made up of five transformational, three transactional and one non-transactional (laissez-faire) leadership factors [3]. Based on this theory, transformational leaders encourage, inspire and excite followers to higher levels of performance [18], are proactive and help their followers to attain unexpected goals [3] and rely on their personal attributes to manage followers [41]. Through TL style, a leader establishes oneself as a role model by gaining trust and confidence of followers [12].

The sub-dimensions of TL include Idealized Influence attribute, Idealized Influence behaviour, Inspirational Motivation, Intellectual Stimulation and Individualized Consideration [11]. Idealized influence attribute refers to the charisma of the leader enabling him to be perceived as confident, powerful and focusing on higher-order ideals and ethics [3]. Through this attribute, the leader acts as a role model by doing the right thing and inspiring the followers to do likewise and thus wins their trust and respect [46]. Idealized Influence behaviour on the other hand describes the leaders' excellent behaviour and willingness to forgo their personal needs to improve the objectives of their workgroup [36]. The leader's ability to articulate an attractive and encouraging vision to followers describes the Inspirational Motivation of the leader [32] who energizes their followers by viewing the future with optimism, stressing ambitious goals, projecting an idealized vision and communicating to followers that the vision is achievable [3]. Such leaders motivate those around them by providing meaning and challenge to their followers' work [9] thus enabling them to perform beyond their expectation.

Intellectual Stimulation enables transformational leaders to challenge old assumptions, take risks, and solicit followers' ideas [32]. Leaders exhibiting this attribute encourage innovation and creativity, create an environment that is tolerant to new ideas and encourage others to consider old problems with a renewed perspective. Through Individualized Consideration leaders contribute to follower satisfaction by advising, supporting and paying attention to their individual needs that allow them to develop and self-actualize [3]. Leaders exhibiting this attribute treat followers as individuals, attend to their unique needs and may delegate certain responsibilities that help them to grow through personal challenges, while acting as mentors or coaches to the followers [11]; [9]; [32].

Transactional leadership is the second part of the FRT of leadership. As contrasted with transformational leaders who rely on their personal attributes to manage followers, transactional leaders use rewards and punishment to strike deals with them and to shape their behaviour [41], thus, depending on the follower's performance, they offer reward or punishment. This leadership style focuses on the leader-follower exchange process; the leader rewards the follower for specific behaviours.

Transactional leadership has three dimensions: contingent reward that describes the degree to which the leader sets up constructive transactions or exchanges with followers by clarifying expectations, establishing the rewards for meeting these expectations [32] and providing followers with material or psychological rewards contingent on the fulfillment of contractual obligations [3]; Active Management-by-exception (MBE) that describes the ability to specify compliance standards, what constitutes ineffective performance and the action to be taken for noncompliance [9] and Passive MBE that describes the behaviour of a leader who does not monitor performance but only intervenes after noncompliance has occurred or when mistakes have already happened. According to Bass [10], active MBE is likely to be more effective than passive MBE.

The third part of the FRT of leadership is the Non-transactional Laissez-faire leadership which represents the absence of transaction of all sorts with respect to leadership [3]. Laissez-faire leaders avoid specifying agreements, clarifying expectations and providing goals and standards to be achieved by followers [9]. This represents the avoidance or absence of leadership and leaders who score high on this style avoid making decisions, hesitate taking action and are absent when needed [32].

Most recent studies in the area of EI and leadership focus on TL as a result of equating effective leaders to those demonstrating TL behaviours [43] and several of them indicate that TL predicts numerous criteria such as follower job satisfaction, leader effectiveness ratings, organizational performance and follower motivation [32]. Popularity of TL style as well as its specific elements that 
Sr. Margaret Chepng'eno \& Dr. Thomas Ngui "Relationship between Emotional Intelligence and Leadership Styles: A Case Study of Leaders in Selected Banking Institutions in Kenya"

are relevant to EI has also led to a keen interest in this form of leadership [27]. Regarding EIleadership styles relationship, the findings of the previous studies are not conclusive and this justifies the need for further research.

\section{Relationship between Emotional Intelligence and Transformational Leadership}

Researchers have recently started to question what influences certain individuals to adopt transformational style of leadership and whether emotional intelligence plays any role in leadership. As a result, many studies that linked EI to TL reported that leaders who considered themselves transformational reported that they were able to identify their own and others' feelings and emotional states, to express their own feelings to others, to use emotional knowledge when solving problems and to effectively manage emotions. Previous studies [34] found that EI predicts TL and that, together with femininity was the most predictive factor of TL accounting for $17 \%$ of variance in this leadership style. Similarly, it has been found that EI is positively related to TL [29] and that it is associated with some aspects of TL [8]. On the contrary, however, other studies found either negative or no relationships between EI and TL. For example, a study conducted [37] revealed that individuals who reported high EI were not more likely to demonstrate TL style. Moreover, no significant correlation for the entire comparison between various dimensions of EI and TL [20] was found. Although most previous researchers used MLQ to identify the managers' perceived leadership styles, they differed on the EI tools used as well as their data source. To evaluate EI, most researchers used ability measures (EQi, MSCEIT and TMMS) and some of them utilized self-assessment data which may have led to exaggerated findings.

Studies that support the relationship between EI and TL indicate that emotional intelligence has a significant positive relationship with at least three dimensions of TL: idealized influence, inspirational motivation and individualized consideration [8]; [40]; [22]. It was found that leaders' EI aspect of self-control and self-management is consistent with idealized influence [8]. When leaders understand their emotions and those of others, they are supportive to their followers and this enhances their trust and confidence on the leaders. Notably, consistent among many studies, inspirational motivation correlates relatively highly with EI. Transformational leaders feel excited, are enthusiastic and energetic and thus revitalize their followers to focus on the vision [16]. The link, therefore, between EI and inspirational motivation is in emotional appeals that transformational leaders use for inspirational motivation [24].

In another study [40] it was found that the ability to monitor and manage emotions were both significantly related to the individualized consideration, implying that EI enables a leader to be aware of others' needs and to react accordingly by being in touch with their emotions. Such leaders are also more likely to subordinate their personal needs in favour of others' [48]. The positive relationship between EI and individualized consideration is strengthened by empathy, which is a dimension of EI that enables leaders to identify with and to show individual concern towards followers.

Intellectual stimulation reveals mixed results in its relationship with EI. Managing emotions promotes positive effect and confidence in followers expressing and generating new ideas [48] and thus intellectual stimulation is expected to be positively related to EI. However, some studies [40]; [8] have found an absence of relationship between this attribute and EI, a situation that may require further investigation. The lack of correlation among the clusters of EI and intellectual stimulation has been attributed to other possible aspects of EI not assessed in the previous studies [40] since creative thinking and flexible planning required for intellectual stimulation [5] have been associated with EI construct, and especially with the ability to use and assimilate emotions and thoughts [47]. Therefore, the absence of relationship between the constructs does not mean that intellectual stimulation is not related to EI. Other researchers [8] attribute the absence of relationship to the nature of intellectual stimulation construct, in the sense that presenting an intellectual challenge and getting people to think about old problems in new ways is more cognitive than the other components of TL and therefore does not rely on individual's EI in the same way that individualized consideration, idealized influence and inspirational motivation do. A more recent study [42] that sought to examine the relations between EI and the components of TL, contrary to the above findings, revealed that there was a significant positive relationship between EI and intellectual stimulation. 
Sr. Margaret Chepng'eno \& Dr. Thomas Ngui "Relationship between Emotional Intelligence and Leadership Styles: A Case Study of Leaders in Selected Banking Institutions in Kenya"

\section{Relationship between Emotional Intelligence and Transactional Leadership}

Although transactional leadership style is often viewed narrowly in terms of leader-follower exchange relationship, it has been suggested that to provide the effective and equitable exchanges characteristic of contingent reward behaviour, leaders should have abilities and traits associated with EI [8]. This might explain the consistent findings among researchers indicating positive correlation between EI and contingent reward. Research has found that contingent reward has a positive relationship with EI at comparable levels to that of TL [27], and that it has a significant positive correlation with the ability to monitor one's emotions and those of others [40]. This construct has also been found to correlate significantly with total TL and several of its components, including idealized influence, inspirational motivation and individual consideration. This, according to the researchers suggests a possibility that "contingent reward" overlaps with the TL components. Another study [10] attributes the positive correlation between EI and contingent reward to the idea that this dimension shares some common aspects of TL.

Active MBE has been found to have no significant relationship with EI, while passive MBE and laissez-faire leadership are known to be negatively related to EI [27]; [22]. According to these studies, leaders who consider themselves as passive are likely to be unable to identify their own feelings and emotions, to understand the emotions of others, to manage emotions and to effectively control them [22].

Contrary to many researchers, a recent study [20] found no relationship between EI and transactional leadership and thus concluded that the importance of EI in leadership is possibly grossly exaggerated. The researchers, however, suggested that the conclusion be taken cautiously as some limitations of MSCEIT with low reliabilities do not allow for such conclusions and instead further research is called for.

\section{Relationship between Emotional Intelligence and Laissez-faire Leadership}

Laissez-faire leadership, just as passive MBE, is a form of non-leadership style and thus it is expected that individuals low on EI would not be effective. Previous studies [29]; [22] reveal negative relationship between laissez-faire leadership and EI implying that leaders who avoid responsibility, who are absent when required, and fail to follow up on request for assistance and resist expression of opinion [10] were more likely unable to identify their own feelings and emotional states, understand the emotions of others, and to effectively control emotional states in the workplace. In some cases, the relationship between laissez-faire leadership and EI is negative but insignificant [29].

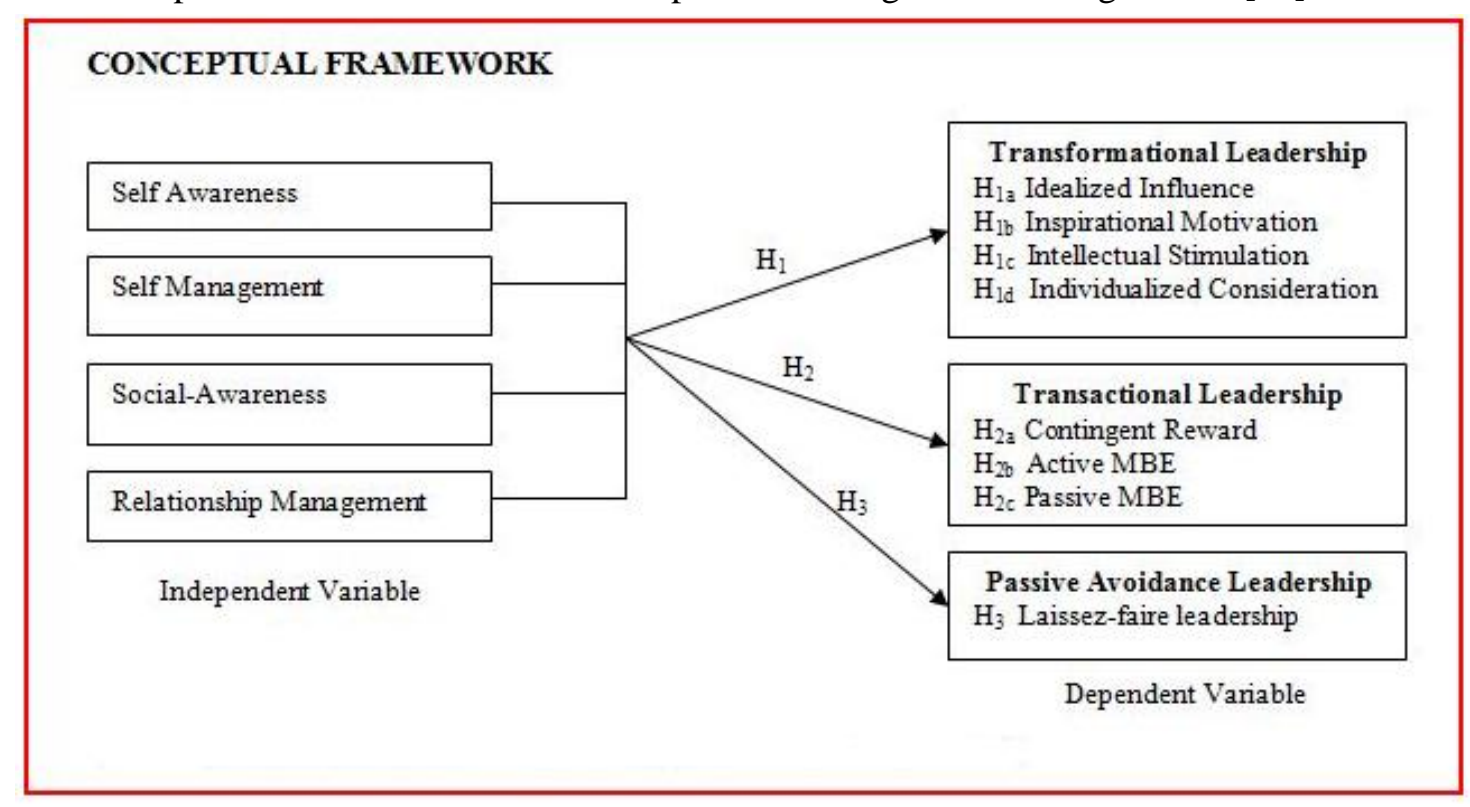

Fig1.0. Relationship between Emotional Intelligence and Leadership Styles

\section{RESEARCH DESIGN}

This study adopted correlational research design since the researcher's objective was simply to determine the relationship between the constructs of interest with no intention to manipulate the 
Sr. Margaret Chepng'eno \& Dr. Thomas Ngui "Relationship between Emotional Intelligence and Leadership Styles: A Case Study of Leaders in Selected Banking Institutions in Kenya"

variables. Survey methodology was used in which case, data were collected through questionnaires distributed among managers/supervisors and their subordinates. Many research studies linking EI to leadership have documented the predominance and suitability of survey methods in obtaining data to measure its relationship with other constructs and this justifies the adoption of this methodology.

Population, Sampling and Sampling Procedure

The target population for this study consisted of leaders, categorized as managers and supervisors of six banks in Kenya with the approximate total population of 400 . The study used a sample size of 300 respondents that composed of 60 leaders and 240 raters. Ten leaders were selected for the study and in addition, four raters per leader were nominated to provide feedback on the EI and perceived leadership styles of the respective leaders. Probability and non-probability sampling techniques were adopted. Convenient sampling was used to identify the banks from which the study would be carried out. Six main banks were targeted based on the researcher's knowledge and familiarity with them. The identification of the banks was influenced by the researcher's judgment that the employees in those banks would be willing to participate in the study since there was heavy reliance on the bank account holders' introduction of the researcher to the management of the banks. Having identified and stratified the sample units, simple random sampling method was applied to pick the ten leaders from each stratum. The leaders were then asked to nominate the raters who would evaluate their level of EI and the leadership styles.

\section{MEASUREMENT OF VARIABLES}

\section{Leaders' Emotional Intelligence}

The leaders' EI scores were evaluated by administering the Emotional and Social Competency Inventory (ESCI) to them as well as their respective raters. This is a 72-item questionnaire developed by the Hay Group [28] The leaders self-rated their emotional quotient using a 5-point Likert-type scale ranging from 1 (never) to 5 (consistently). Similarly, four raters evaluated each leader's level of EI using the same scale. The score for each item in the questionnaire was obtained by summing up the average scores of the raters (self and others) and dividing by two. Subsequently, the total average score of each EI cluster was obtained by summing up the average scores of the raters (self and others) and then dividing by the number of questions in each cluster. The overall average EI score of an individual leader was obtained by summing up the individual's self assessment average score and the total raters' average score for all clusters and dividing it by two.

\section{Perceived Leadership Styles}

Multifactor Leadership Questionnaire (MLQ-5X) was administered to the four raters of each leader. The various dimensions of each leadership style were measured using 45 items and the raters evaluated each leader using a 5-point Likert-type scale ranging from 0 (not at all) to 4 (frequently, if not always). The mean score of each dimension was obtained by calculating the average values of all raters for the items and then divided by four - the number of raters

\section{Reliability and Validity of Research Instruments}

This study relied on the psychometric property analysis of previous researchers on the reliability and validity of ESCI and MLQ. Internal consistency estimates (Cronbach's alpha values) for ESCI subscales have been found to range from .79 to .91 [14], indicating that the instrument is acceptably reliable. Similarly, Cronbach's alpha values for MLQ subscales ranged from .70 to .94 [49]. Thus, the internal consistency reliability for ESCI and MLQ are generally above the acceptable minimum standard of .70 recommended [33]. Besides, a pilot test was conducted by administering the questionnaires to a small sample of twenty $(n=20)$ respondents (who would not take part in the actual research) from two banks located in Nairobi county and the scores were meaningful; the questionnaires were duly filled and the responses proved helpful in drawing conclusions. The validity of ESCI and MLQ is also guaranteed since many researchers and scholars have used them to test EI and leadership style constructs and there is documentation to that effect. ESCI is supported by robust validity evidence from research in a variety of organizational contexts worldwide [15]. MLQ is also a well-established tool that has been used in a variety of settings and broad population, such as industry, military, primary and secondary schools, marketing and higher education organizations in different countries [3]. Many studies have also used it as a measure of leadership effectiveness [29]; [34]; [39]; [20]. 
Sr. Margaret Chepng'eno \& Dr. Thomas Ngui "Relationship between Emotional Intelligence and Leadership Styles: A Case Study of Leaders in Selected Banking Institutions in Kenya”

\section{RESERCH FINDINGS}

Out 60 sets of questionnaires distributed, 52 were collected duly filled and these were used for analysis. The raw data were entered into the computer, grouped into clusters making up components of EI and leaderships styles, and their average scores calculated. These were then recorded and analyzed using Statistical Package for Social Sciences (SPSS).

Hypothesis $1\left(\mathrm{H}_{1}\right)$ stated a positive relationship between EI and TL style. To test this hypothesis, the Spearman's Correlation was run between the 52 leaders' overall EI score and TL style. The results indicated a moderately strong positive relationship, which was statistically significant $\left(r_{s}=0.424 . p=\right.$ 0.001 ) as shown in table 1.0, and therefore hypothesis 1 was supported.

Table1.0. Relationship between EI and Transformational Leadership

\begin{tabular}{|l|l|l|r|r|}
\hline \multicolumn{5}{|c|}{ Correlations } \\
\hline \multirow{3}{*}{ Spearman's rho } & \multirow{3}{*}{ EI Score } & EI Score & TL \\
\cline { 3 - 5 } & & Correlation Coefficient & 1.000 & $.424^{* *}$ \\
\cline { 3 - 5 } & Sig. (1-tailed) &. & .001 \\
\cline { 3 - 5 } & $\mathrm{N}$ & 52 & 52 \\
\hline
\end{tabular}

**. Correlation is significant at the 0.01 level (1-tailed).

Leaders who scored highly on EI were perceived as transformational, thus supporting the findings of several previous studies on EI-TL relationship, although with some variations. In their study, Hunt and Fitzgerald [31] found that studies that utilized small samples $(n<50)$ and that used same-source data reported a positive relationship between EI and TL style. On the contrary, studies that used multi-source data from larger samples found little support for this relationship. The results of the current study that used multi-rater assessment data from a sample of 52 indicated a positive relationship between the variables, hence supporting the findings of the researchers that used leader self-assessment data. This confirms that EI plays a role in predicting TL style. Leaders who are in touch with their own and others' emotions and who are able to manage these emotions create an enabling relationship that inspires and motivates their followers to improved performance.

Further analysis on the relationship between EI and the various components of TL was conducted by running multiple correlations among the clusters of EI and the five components of TL (table 2.0). The correlations revealed positive significant relationships among the four clusters of EI: Self-Awareness, Self-Management, Social Awareness and Relationship Management, and idealized influence attribute (IA), idealized influence behaviour (IB), inspirational motivation (IM) and individualized consideration (IC). Highest correlations, however, were found to exist among Relationship Management and idealized influence, inspirational motivation and individualized consideration. Although positive correlations among EI clusters and intellectual stimulation existed, the relationships were insignificant.

Table2.0. Correlations among EI and Transformational Leadership dimensions

\begin{tabular}{|c|c|c|c|c|c|c|c|}
\hline \multicolumn{8}{|c|}{ Correlations } \\
\hline & & & IA & IB & IM & IS & $\mathrm{IC}$ \\
\hline \multirow{8}{*}{ Spearman's rho } & \multirow{2}{*}{ Self-Awareness } & Correlation Coefficient & $.399^{* *}$ & $.369^{* *}$ & $.393^{* * *}$ & .143 & $.413^{* *}$ \\
\hline & & Sig. (1-tailed) & .002 & .004 & .002 & .156 & .001 \\
\hline & \multirow{2}{*}{ Self-Management } & Correlation Coefficient & $.549^{* * *}$ & $.483^{* * *}$ & $.561^{* * *}$ & .210 & $.372^{* * *}$ \\
\hline & & Sig. (1-tailed) & .000 & .000 & .000 & .068 & .003 \\
\hline & \multirow{2}{*}{ Social Awareness } & Correlation Coefficient & $.506^{* *}$ & $.496^{* *}$ & $.557^{* *}$ & .008 & $.443^{* *}$ \\
\hline & & Sig. (1-tailed) & .000 & .000 & .000 & .478 & .001 \\
\hline & \multirow{2}{*}{$\begin{array}{l}\text { Relationship } \\
\text { Management }\end{array}$} & Correlation Coefficient & $.566^{* *}$ & $.498^{* *}$ & $.587^{* *}$ & .087 & $.650^{* *}$ \\
\hline & & Sig. (1-tailed) & .000 & .000 & .000 & .269 & .000 \\
\hline
\end{tabular}

**. Correlation is significant at the 0.01 level (1-tailed).

*. Correlation is significant at the 0.05 level (1-tailed).

The positive relationships among EI clusters and the components of TL further confirm the findings of previous studies that reported positive correlations between EI and idealized influence, inspirational motivation and individualized consideration [8]; [40]; [22]. Effectively managing emotions empowers leaders to win the trust and confidence of their followers, to project an attractive vision and to instill confidence in others that such a vision is achievable. Emotionally intelligent 
Sr. Margaret Chepng'eno \& Dr. Thomas Ngui "Relationship between Emotional Intelligence and Leadership Styles: A Case Study of Leaders in Selected Banking Institutions in Kenya"

leaders also appreciate the uniqueness of others and so will treat them as individuals; not just as members of a group. The link between EI and individualized consideration is in leaders' traits of being appreciative, compassionate and responsive to the individual needs of others.

The highest positive correlations among Relationship Management and TL components have important implications; leadership nests in EI's Relationship Management captured in influence, ability to coach and mentor, conflict management, inspirational leadership and teamwork skills. Since leadership is influence, the leader's ability to influence others rests on maintaining and managing relationship with them, hence, leaders with a positive impact on others and who persuade them to gain their support are effective leaders capable of inspiring and guiding others towards achievement of goals. This highest correlation therefore implies that leaders who are capable of managing emotions in their relationship win the trust and confidence of followers, and create conducive environment for the achievement of goals.

The second hypothesis $\left(\mathrm{H}_{2}\right)$ stated a positive relationship between EI and Transactional leadership style. While the correlation results between the overall EI scores and transactional leadership indicated a positive insignificant relationship between the variables $\left(r_{s}=0.118, p=0.202\right)$ as depicted in table 3.0, the correlations among each of the four clusters of EI and the three components of Transactional Leadership Style: Contingent Reward (CR), Active and Passive MBE showed that there were significantly positive correlations between the EI clusters and Contingent Reward (CR) as well as between EI clusters and Active MBE (table 4.0). Both Contingent Reward and Active MBE correlated highly with Self-Awareness component of emotional intelligence $\left(r_{s}=0.507, p=0.000\right.$ and $r_{s}=0.460, p=.000$ respectively). Further analysis revealed that there was a negative insignificant relationship between the four clusters of EI and Passive MBE.

Table3.0. Relationship between EI and Transactional Leadership Style

\begin{tabular}{|l|l|l|r|r|}
\hline \multicolumn{4}{|c|}{ Correlations } \\
\hline \multirow{2}{*}{ Spearman's rho } & \multirow{3}{*}{ EI Score } & Correlation Coefficient & EI Score & \multicolumn{1}{c|}{ TSLeadership } \\
\cline { 3 - 5 } & & Sig. (1-tailed) & 1.000 & .118 \\
\cline { 3 - 5 } & & $\mathrm{N}$ & 5 & .202 \\
\hline
\end{tabular}

Table4.0. Relationships among EI and Transactional Leadership components

\begin{tabular}{|c|c|c|c|c|c|}
\hline \multicolumn{6}{|c|}{ Correlations } \\
\hline & & & Contingent Reward & Active MBE & Passive MBE \\
\hline \multirow{8}{*}{ Spearman's rho } & \multirow{2}{*}{$\begin{array}{l}\text { Self- } \\
\text { Awareness }\end{array}$} & Correlation Coefficient & $.507^{* * *}$ & $.460^{* *}$ & -.072 \\
\hline & & Sig. (1-tailed) & .000 & .000 & .307 \\
\hline & \multirow{2}{*}{$\begin{array}{l}\text { Self- } \\
\text { Management }\end{array}$} & Correlation Coefficient & $.456^{* *}$ & $.338^{* *}$ & -.123 \\
\hline & & Sig. (1-tailed) & .000 & .007 & .192 \\
\hline & \multirow{2}{*}{$\begin{array}{l}\text { Social } \\
\text { Awareness }\end{array}$} & Correlation Coefficient & $.410^{* * *}$ & $.304^{*}$ & -.114 \\
\hline & & Sig. (1-tailed) & .001 & .014 & .210 \\
\hline & \multirow{2}{*}{$\begin{array}{l}\text { Relationship } \\
\text { Management }\end{array}$} & Correlation Coefficient & $.346^{* *}$ & $.296^{*}$ & -.040 \\
\hline & & Sig. (1-tailed) & .006 & .017 & .389 \\
\hline
\end{tabular}

**. Correlation is significant at the 0.01 level (1-tailed).

*. Correlation is significant at the 0.05 level (1-tailed).

Many previous studies found that contingent reward positively related to EI at comparable levels to that of TL, leading some scholars to argue that this dimension overlaps with TL components; more so because apart from its relationship with EI, it correlates significantly with total TL and with several of its components. Emotionally intelligent leaders clearly stipulate the standards of performance, monitor performance and reward achievement of goals implying that EI supports certain transactional leadership elements, for example, when they use the contingent reward characteristic in order to inspire and motivate followers to perform well. This is important for organizational success because by combining transactional leadership and EI, employees will be more committed to their job and this increases their job performance. Because of EI, transactional leaders make and fulfill promises by rewarding employees appropriately and linking those rewards to performance. This inspires involvement, loyalty, commitment and performance from the followers. This study further found that contingent reward correlates highly with all the components of TL confirming that it might represent another subcomponent of TL as suggested by previous researches [8]. 
Sr. Margaret Chepng'eno \& Dr. Thomas Ngui "Relationship between Emotional Intelligence and Leadership Styles: A Case Study of Leaders in Selected Banking Institutions in Kenya"

Contrary to some studies [27] that found no relationship between active MBE and EI, the current study revealed a significant positive relationship between the variables. Active MBE describes leaders who closely monitor performance and intervene readily whenever there are deviations. Achievement oriented leaders actively monitor performance so as to ensure achievement of goals, and so EI is expected to be positively related with active MBE. Emotionally intelligent managers monitor performance and ensure things are done as per standards. Being aware of what goes on around them enables them to decide when and how to intervene whenever deviations are perceived. The negative relationship between EI and Passive MBE indicates that emotionally intelligent leaders are proactive and thus do not wait for things to go wrong before taking action.

The third hypothesis $\left(\mathrm{H}_{3}\right)$ stated a negative relationship between EI and Laissez-faire Leadership style. Contrary to the hypothesis, the correlation between the total EI scores of leaders and laissez-faire leadership (LFL) revealed a positive non significant relationship $\left(r_{s}=0.067, p=.317\right)$ as shown in table 5.0. However, the correlation results between each of the four clusters of EI and laissez-faire leadership style indicated a significant negative relationship (table 6.0). This supports the findings of previous studies and implies that emotionally intelligent leaders will neither avoid responsibility nor be absent when required and will not take a passive role in leadership. Such leaders have high relationship management traits like mentoring and coaching, team-working and influencing others by working with them towards shared goals; on the contrary, leaders avoiding responsibility are unable to understand their own and others' feelings and emotions and to effectively control them [10].

Table5.0. Relationship between EI and Laissez-faire Leadership

\begin{tabular}{|c|c|c|c|c|}
\hline \multicolumn{5}{|c|}{ Correlations } \\
\hline & & & EI Score & Laissez-faire Leadership \\
\hline \multirow{3}{*}{ Spearman's rho } & \multirow{3}{*}{ EI Score } & Correlation Coefficient & 1.000 & .067 \\
\hline & & Sig. (1-tailed) & . & .317 \\
\hline & & $\mathrm{N}$ & 52 & 52 \\
\hline
\end{tabular}

Table6.0. Correlations among EI clusters and Laissez-faire Leadership

\begin{tabular}{|c|c|c|c|}
\hline \multicolumn{4}{|c|}{ Correlations } \\
\hline & & & Laissez-faire Leadership \\
\hline \multirow{8}{*}{ Spearman's rho } & \multirow{2}{*}{ Self-Awareness } & Correlation Coefficient & $-.357^{* * *}$ \\
\hline & & Sig. (1-tailed) & .005 \\
\hline & \multirow{2}{*}{ Self-Management } & Correlation Coefficient & $-.371^{* *}$ \\
\hline & & Sig. (1-tailed) & .003 \\
\hline & \multirow{2}{*}{ Social Awareness } & Correlation Coefficient & $-.311^{*}$ \\
\hline & & Sig. (1-tailed) & .012 \\
\hline & \multirow{2}{*}{ Relationship Management } & Correlation Coefficient & $-.409^{* *}$ \\
\hline & & Sig. (1-tailed) & .001 \\
\hline
\end{tabular}

**. Correlation is significant at the 0.01 level (1-tailed).

*. Correlation is significant at the 0.05 level (1-tailed).

\section{DISCUSSION AND RECOMMENDATIONS}

This study provides supporting evidence for the claim of the importance of EI in leadership process. Emotional Intelligence's positive relationship with transformational leadership implies that companies should incorporate it in their selection of employees for leadership positions. Banks should also consider interventions for training employees on strategies for developing and nurturing their EI so as to build an awareness of emotional aspects of leadership competencies in order to respond to the growing complexity of businesses.

The relationship between EI and intellectual stimulation warrants further investigation. Contrary to prior studies that found no relationship between EI and this construct, the current study revealed an insignificant positive relationship. Intellectual stimulation describes open-minded leaders who encourage creativity and innovation through critical thinking. Emotionally intelligent leaders are expected to be open-minded and tolerant to new ideas and therefore the insignificant positive relationship, and more so, the absence of relationship revealed in the previous studies, is a matter that requires further study.

Although transactional leadership style has been criticized for leading followers to short-term relationships of exchange with the leader [18] it has some benefits as well and organizations should 
Sr. Margaret Chepng'eno \& Dr. Thomas Ngui "Relationship between Emotional Intelligence and Leadership Styles: A Case Study of Leaders in Selected Banking Institutions in Kenya"

not ignore it. The positive relationship between emotional intelligence and contingent reward as well as active management by exception implies that organizations can leverage on these attributes to clearly define performance standard, actively monitor performance and reward achievement of goals.

\section{CONCLUSIONS}

The results of this study supported many previous studies by confirming a positive relationship between EI and TL. Multiple correlations among the EI clusters and TL components indicated significantly positive relationship among all the variables. However, highest correlation was found to exist between Relationship Management and TL style clusters. Regarding Transactional Leadership style there were significant positive relationships between EI and Contingent Reward and Active MBE, with Contingent Reward highly correlating with Self-Awareness component of EI. On the other hand, the relationship between EI and Passive MBE was negative but insignificant. A correlation between the overall EI scores of leaders and Laissez-faire leadership indicated an insignificant positive relationship while EI clusters had significant negative relationships with laissezfaire leadership, implying that EI is negatively related to passive avoidant leadership.

This study provides evidence that individuals with high levels of EI are more likely to adopt the TL style ideal for banking institutions. Such individuals are also able to clearly specify performance standards, to monitor performance and to reward achievement of goals, all of which have positive effects on the performance. Leaders who abscond their responsibility, who avoid making decisions and who are passive in leadership do not facilitate achievement of goals and these are associated with individuals with low levels of EI.

\section{REFERENCES}

[1] Antonakis, J. (2009). "Emotional intelligence": What does it measure and does it matter for leadership? In G. B. Graen (Ed). LMX leadership-Game-Changing Designs: Research-Based Tools (Vol. VII) (pp. 163-192). Greenwich, CT: Information Age Publishing

[2] Antonakis, J. (2003). Why "Emotional Intelligence" Does not predict Leadership Effectiveness: A Comment on Prati, Douglas, Ferris, Ammeter, and Buckley (2003). The International Journal of Organizational Analysis, 3, 355-361

[3] Antonakis, J., Avolio, B. J., \& Sivasubramaniam, N. (2003). Context and leadership: an examination of the nine-factor full-range leadership theory using the Multifactor Leadership Questionnaire. The Leadership Quarterly, 14, 261-295.

[4] Avolio, B. (1994). The "natural": Some antecedents to transformational leadership. International Journal of Public Administration, 17, 1559-1581.

[5] Avolio, B., Waldman, D. and Yammarino, F. (1991), Leading in the 1990s: the four I's of transformational leadership, Journal of European Industrial Training, 15, 9-16

[6] Awamleh, R., Evans, J., Mahate, A. (2005).A Test of Transformational and Transactional Leadership Styles on Employees' Satisfaction and Performance in the UAE Banking Sector. Journal of Comparative International Management, 8, 3-19

[7] Babooa, S.K. (2013). Modern Leadership Development and Excellence: Leadership Excellence. AuthorHouse: Bloomington

[8] Barling, J., Slater, F. \& Kelloway, E. K. (2000). Transformational leadership and emotional intelligence: an exploratory study, Leadership and Organization Development Journal, 21, 157161

[9] Bass, B. M., Avolio, B. J., Jung, D. I., \& Berson, Y. (2003). Predicting unit performance by assessing transformational and transactional leadership. Journal of Applied Psychology, 88, 207218

[10] Bass, B. M. (1999). Two decades of research and development in transformational leadership. European Journal of Work and Organizational Psychology, 8, 9-32

[11] Bass, B. M., \& Avolio, B. J. (1994). Improving organizational effectiveness through transformational leadership. Thousand Oaks, CA: Sage Publications.

[12] Bass, B.M. (1985). Leadership and Performance Beyond Expectations. New York: Free Press.

[13] Bono, J.E. \& Judge, T.A. (2004). Personality and transformational and transactional leadership: A meta-analysis, Journal of Applied Psychology, 89 (5): 901-910. 
Sr. Margaret Chepng'eno \& Dr. Thomas Ngui "Relationship between Emotional Intelligence and Leadership Styles: A Case Study of Leaders in Selected Banking Institutions in Kenya"

[14] Boyatzis, R.E. \& Gaskin, J. (2010). A technical note on the ESCI/ESCI-U reliability and factor structure. Hay Group research report

[15] Boyatzis, R.E. \& Goleman, D. (2007). Emotional and Social Competency Inventory (ESCI) User Guide. Hay Group (2011)

[16] Brief A.P., Weiss H.M.(2002) Organizational behavior: Affect in the workplace. Annu Rev Psychol. 53:279-307

[17] Bumphus, A.T. (2008). The Emotional Intelligence and Resilience of School Leaders: An Investigation into Leadership Behaviours. UMI Microform 3329731. Ann Arbor, MI: ProQuest LLC

[18] Burns. J.M. (1978). Leadership. New York: Harper \& Row

[19] Bushra, F., Usman, A., Naveed, A. (2011). Effect of Transformational Leadership on Employees' Job Satisfaction and Organizational Commitment in Banking Sector of Lahore (Pakistan). International Journal of Business and Social Science, 2, 261-267

[20] Chatterjee, A. \& Kulakli, A. (2015). An Empirical Investigation of the Relationship Between emotional Intelligence, Transactional and Transformational Leadership Styles in Banking Sector. Procedia - Social and Behavioural Sciences 210, 291-300

[21] Ciulla, J.B. (1998). Ethics: The Heart of Leadership. Praeger, Westport, CT

[22] Gardner, L. \& Stough, C. (2002). Examining the relationship between leadership and emotional intelligence in senior level managers, Leadership and Organization Development Journal, 23, 68-78

[23] Garg, S. \& Jain, S. (2013). Mapping Leadership Styles of Public and Private Sector Leaders Using Blake and Mouton Leadership Model. A Management Journal, 4, Sept. 2012-March 2013

[24] George, J.M. (2000). Emotions and Leadership: The Role of Emotional Intelligence. Human Relations, 53, 1027-1055

[25] Goleman, D. (2001). Emotional intelligence: Issues in paradigm building. In Cherniss, C. \& Goleman, .D (Ed's.), The Emotionally Intelligent Workplace. San Francisco: Jossey-Bass.

[26] Guay, R.P. (2013). The Relationship between leader fit and Transformational leadership. Journal of Managerial psychology, 28, 55-73

[27] Harms, P.D. \& Credè (2010). Emotional Intelligence and Transformational and Transactional Leadership: A Meta-Analysis. Journal of Leadership \& Organizational Studies, 17, 5-17

[28] Hay Group (2011). Emotional and Social Competency Inventory (ESCI): A User Guide for Accredited Practitioners

[29] Hebert, E.B. (2011). The Relationship between Emotional Intelligence, Transformational Leadership, and Effectiveness in School Principals. Dissertation, Georgia State University

[30] Hudson, V.M. (2007). Foreign Policy Analysis: Classic and Contemporary Theory. New York: Rowman \& Littlefield Publishers, Inc.

[31] Hunt, J.B. \& Fitzgerald, M. (2013). The Relationship between Emotional Intelligence and Transformational Leadership: Investigation and Review of Competing Claims in the Literature, American International Journal of Social Science, Vol. 2

[32] Judge, T.A. \& Piccolo, R.F. (2004). Transformational and Transactional Leadership: A MetaAnalytic Test of their Relative Validity, Journal of Applied Psychology, 89, 755-768

[33] Loewenthal, K.M. (2001). An Introduction to Psychological Tests and Scales (2 ${ }^{\text {nd }}$ Ed.). Philadelphia: Psychology Press Ltd.

[34] Lopez-Zafra, E., Garcia-Retamero, R. \& Martos, M. (2012). The relationship between transformational leadership and emotional intelligence from a gendered approach, The Psychological Record, 62, 97-114.

[35] McDermott, R. (2004). Political Psychology in International Relations. Michigan: University of Michigan Press

[36] Moss, S. A., \& Ritossa, D. A. (2007). The impact of goal orientation on the association between leadership style and follower performance, creativity and work attitudes. Leadership \& Organization Development Journal, 3, 433-456 
Sr. Margaret Chepng'eno \& Dr. Thomas Ngui "Relationship between Emotional Intelligence and Leadership Styles: A Case Study of Leaders in Selected Banking Institutions in Kenya"

[37] Moss, S., Ritossa, D. \& Ngu, S. (2006). The effect of follower regulatory focus and extraversion on leadership behaviour: The role of emotional intelligence, Journal of individual Differences, 27, 93-107

[38] Nye, C. (2008). The Powers to lead. New York: Oxford University Press.

[39] Owoseni \& Olakitan, O. (2014). Emotional Intelligence and Perceived Leadership Behaviour Effectiveness in Organizations. International Journal of Humanities and Social Science, 4, No, 2 (Special Issue)

[40] Palmer, B., Walls, M., Burgess, Z. \& Stough, C. (2001). Emotional intelligence and effective leadership, Leadership and Organization Development Journal, 22, 5.

[41] Quick, J.C. and Nelson, D.L. (2011). Principles of Organizational Behaviour: Realities and Challenges. UK: South-Western Cengage Learning

[42] Rahman, M.S., Ferdausty, S., \& Uddin, M.A. (2012). Examining the Relationships between Emotional Intelligence and the Components of Transformational Leadership. ABC Journal, 32, 45-59

[43] Rosete, D. (2007). Does Emotional Intelligence Play an Important Role in Leadership Effectiveness? University of Wollongong Thesis Collections

[44] Riaz T., Akram M.U., Ijaz H. (2011). Impact of transformational leadership style on affective employees commitment: an empirical study of banking sector in Islamabad (Pakistan). The Journal of Commerce, 3, 43-51

[45] Rubin, R. S., Munz, D. C., \& Bommer, W. H. (2005). Leading from within: The effects of emotion recognition and personality on transformational leadership. Academy of Management Journal, 48, 845-858.

[46] Sadeghi, A. \& Pihie, Z.A.L. (2012). Transformational Leadership and Its Predictive Effects on Leadership Effectiveness. International Journal of Business and Social Science, V.3

[47] Salovey, P., \& Mayer, J.D. (1990). Emotional intelligence. Imagination, Cognition, and Personality, 9, 185-211.

[48] Sosik, J. J., \& Megarian, L. E. (1999). Understanding leader emotional intelligence and performance: The role of self-other agreement on transformational leadership perceptions. Group Organization Management, 24, 367-390.

[49] Tejeda, M.J., Scandura, T.A., \& Pillai, R. (2001). The MLQ revisited Psychometric Properties and Recommendations. The Leadership Quarterly, 12, 31-52

[50] Yukl, G. (2010). Leadership in Organizations ( $7^{\text {th }}$ Ed.). New York: Pearson

\section{AUTHORS' BIOGRAPHY}

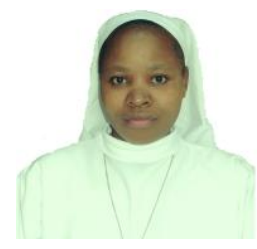

Sr. Margaret Chepng'eno, lectures at the Catholic University of Eastern Africa and is currently in charge of the Human Resources at Christamarianne Mission Hospital, Kenya. She holds a Master's Degree (Human Resource Management) from The Catholic University of Eastern Africa.

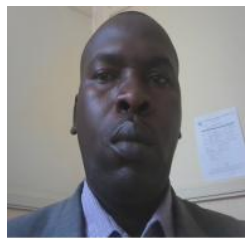

Dr. Thomas Ngui, is a Lecturer and the Head of the Department of Marketing and Management at The Catholic University of Eastern Africa. He holds a Ph.D (Human Resources Management) from Jomo Kenyatta University of Agriculture and Technology. Dr. Ngui has published widely in the area of Management, Corporate Governance, Human Resources Management, Entrepreneurship and Educational Management. 